\title{
Ditransitive Verbs: An English Print Media based Comparison of Pakistani English and British English
}

\author{
Asadullah Balouch \\ Lecturer, Army Public School \& College Petaro, Sindh Pakistan \\ Dr. Farida Panhwar \\ Assistant Professor, Institute of English Language and Literature, University of Sindh Jamshoro \\ Pakistan
}

\begin{abstract}
The present study highlights the ditransitive complementation between Pakistani English (PE) and British English (BE). The ditransitive verb complementation allows double objects in a sentence i.e. indirect object and direct object. Since the current study uses qualitative research methodology, a sample of 48 statements selected from these Pakistani Print Media sources: one newspaper, six daily magazines and two weekly magazines; eventually, 8 statements out of the 48 statements were only found suitable. Although, the findings of the present paper may be generalized as per the nature of study. Moreover, the retrieved data is analyzed in correspondence with the three patterns of ditransitive complementation of BE as introduced by Rahman (1990). Finally, the findings of the current study showed that PE utilizes infinitive phrase at the place of direct object; in view of second pattern PE leaves out indirect object and that clause remains the same between the two mentioned Englishes. Hence, in view of the third and last pattern, PE applies to infinitive in the place of indirect object and prepositional idiom. The study, hereby, has been successful in identifying the ditransitive complementation deviations between PE and BE.
\end{abstract}

Keywords: Ditransitive Complementation, sentential, inter-sentential, double objects, infective phrase.

\section{INTRODUCTION}

Having considered Pakistani English (PE) and British English (BE), this research paper identifies ditransitive verb complementation using PE Print Media. The study has covered PE newspapers, dailies and weekly magazines. Certainly, several researchers (Baumgardner, 1987, 1990, 1993; Mahboob, 2003; Rahman, 1990) have identified deviations between PE and BE with respect to the sentential, inter-sentential level, lexical, and phonological level. Moreover, the study also discusses earlier studies related to the variations between PE and BE in terms of ditransitive verb complementation. The next section discusses language variation in the light of sociolinguistics.

\subsection{Language Variations}

Pakistan with respect to sociolinguistics and anthropology is classified as a multilingual, multiethnic, and multicultural country where people speak one indigenous language as mother 
tongue, Urdu, the official language as well as lingua franca of the state while educated people can use English, the second official language and sole code of communication in the domains of education, commerce, judiciary, army and politics etc. (Rahman, 1996).

Investigating language variation has got prime importance in the field of sociolinguistics in which researchers examine the linguistic variations in terms of pronunciation, lexemes, discourse registers etc. Linguists also explore the social, political, cultural and religious factors contributing that make PE as a distinct variety (Aziz \& Mahmood, 2012). Having considered English in view, it is a unique language which has got various varieties and these varieties are studied under the paradigm of World Englishes (Aziz \& Mahmood, 2012).

The researchers like Talaat $(2002,1993,1988)$ and Baumgardner (1993, 1990, 1987) have identified various variations like phonological, morphological, lexical, including ditransitive verb complementation related to PE but which are not only based on intuition and these findings are comprised of limited data and samples (Aziz \& Mahmood, 2012). As many studies (Malchukov, Haspelmath, \& Comrie, 2010; Boyadzhieva, 2009) notified that ditransitive complementation includes three arguments: the first one is an agent argument (A), the second one is a recipient-like $\operatorname{argument}(\mathrm{R})$, and the last one is a theme argument $(\mathrm{T})$.

e.g. Abid (A) sent Hamid (R) a letter (T).

Above sentence shows that the ditransitive keeps double objects in which the first object is defined as indirect object which is mentioned as beneficiary in the sentence whereas the second object is defined as the direct object which makes complete sense of the sentence.

Furthermore, it is vindicated by Pastor (2009) that language variation takes place due to the use of English as a lingua franca. Language variation enriches international language as it is used by international writers and it also makes possible to convey one concept in different ways. Also, he asserts that language variation is caused by the influence of mother tongue as nonnative writers and speakers transmit their own language model when they write and speak in the target language (Pastor, 2002; 2005; 2007).

Newman (1996) states that the objects are to be moved between agents while using ditransitive verb. In this regard, Qi (2013) advocates that ditransitive verbs make possible two types of constructions viz. the double object construction (DOC) and the prepositional dative construction (DAT). Additionally, ditransitive verb may change sentence into three types of passive structures (Boyadzhieva, 2009).

Conversely, since editorial guidelines do not allow researchers to follow up language variation, nonnative writers face severe difficulty when they write research papers. They revise several times their write-up, so that their work may meet with the required standards in the international style of journals leaded by American and British committees (Pastor, 2009). Similarly, another study 
Carrió-Pastor (2013) identifies the factors which cause linguistic variation in which the linguistic background of the writers and mother tongue of the nonnative speakers and writes are the dominant. The following section discusses objectives of the study.

\subsection{Objective/s}

The present paper investigates the deviations of ditransitive verb complementation between PE and BE using PE newspapers, dailies and weekly, so that the new researchers may get better understanding about ditransitive verb deviations.

\subsection{Research Questions}

RQ1: What are ditransitive verb deviations between Pakistani English and British English using Pakistani English Print Media?

\section{REVIEW OF LITERATURE}

\subsection{Pakistani English and British English}

World Englishes as a separate discipline of studies of issues in applied linguistics makes vivid that the varieties of English are caused by the sociocultural, religious, political and historical dimensions of the world (Crystal, 1999; Kachru, 1990). These varieties of English vary in terms of phonetics, lexemes, syntax, semantics and pragmatics. An Indian linguist, Kachru (1990) classified World Englishes into three layers by giving the title of three concentric circles in which the inner circle is comprised of these countries (e.g., the USA, the UK, Australia, etc.) whereas the outer circle is comprised of these countries (e.g., Bangladesh, Pakistan, India, etc.) and the expanding circles is comprised of these countries (e.g., China, Egypt, Japan, Saudi Arabia, etc.). Moreover, the countries in the model of three concentric circles were sorted out in terms of the geographical representation as well as sociopolitical and historical background. As the inner circle covers such countries where English is used as their first language and they are the "normproviding' countries whereas the outer circle covers such countries which were ex-colonies of the UK or the USA and therein English is used as official language and is spoken as well as learned outside of classroom due to its privilege in the domains of power and unlike previous two circles, the expanding circle covers such countries which are not ex-colonies of British Raja and therein English is only taught as a subject not as a language; besides, they are not encouraged to talk in English outside of classroom (Kirkpatrick, 2007). The diagram of concentric circles is given below: 


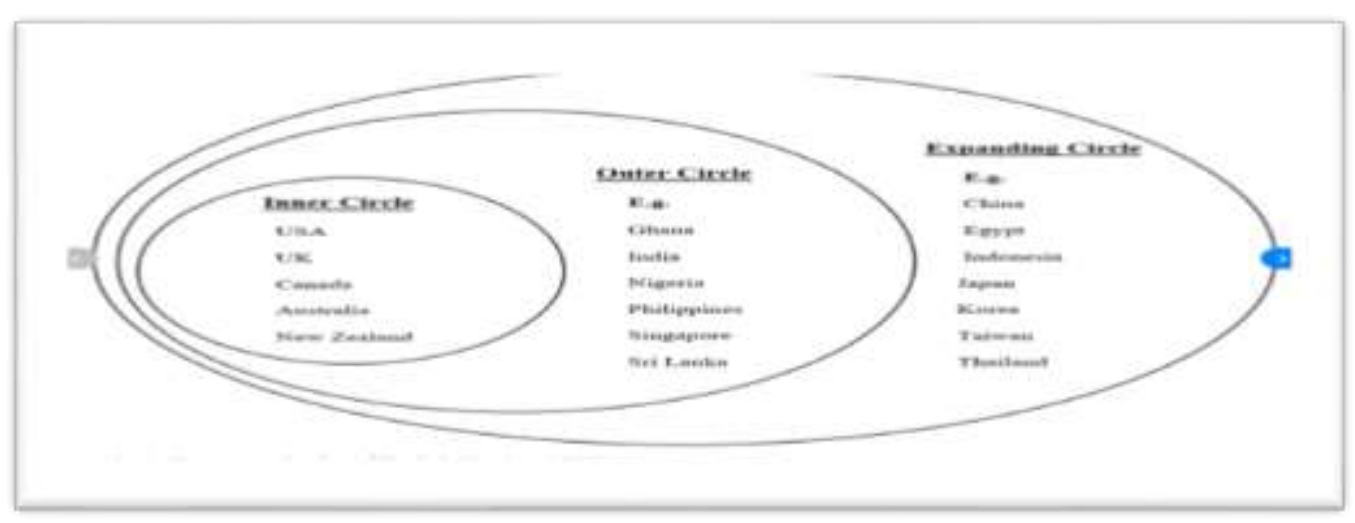

Concentric Circle Model (Kachru, 1992)

Kachru (2005) and other peripheral linguists (Dissanagake, 1997; Thumboo, 1992) have acknowledged the presence of World Englishes and they claim that all the existing varieties of English differ from one another with respect to these features: phonology, lexemes, semantics, grammar, morphology, discourse structures, registers, styles, and syntactic representation. In the same manner, it is stated that Englishisation does not only cover phonological and lexical deviations, but it also covers grammar, discourse registers, styles, and genres of English world literature (Kachru, 2006).

Having considered world Englishes, PE and BE differ from each other at both the sentential and clausal level (Mahboob, 2003). Mehboob also identifies that PE and BE Englishes vary from each other in terms of word-order at the sentential level likewise vary from each other in terms of the rules of complementation at the clausal level.

\subsection{Complementation as a Syntactic and Grammatical Aspect}

Many researchers have investigated various deviations between PE and BE namely, phonologically, morphologically, semantically, grammatically, syntactically, style, and registers (Baumgardner, 1987; Uzair, Mahmood, \& Khan, 2012). Complements with respect to Valency theory (Ágel, \& Fischer, 2009; Herbst, Heath, Roe, \& Götz, 2004), subject agrees with the verb with respect to the number and type of elements; so that, to form grammatically correct sentence. In the same manner, Homberger (2001) delineates that the valency theory emphasizes that the verb plays a fundamental role in every sentence to make grammatically well-formed structure as it decides how many other words can make sentence correct. The complements are usually classified into two categories: nominal complements and clausal complements. Nominal complements are based on noun phrases whereas clausal complements are based on wh-clauses or to-infinitives (Salonen, 2009).

Moreover, Quirk, Leech, and Svartvik (1985) proposed four main types of verb complementation: i. Copular, ii. Monotransitive, iii. Complex transitive and iv. Ditransitive. Ditransitive Complementation is seen such sentences which keep two objects: direct and indirect object. The indirect object precedes direct object and direct object complements indirect in such sentences. For example: a) They taught the new student [Indirect object] English grammar [Direct object]., b). 
They taught English grammar [Direct object] to the new students [Prep. Ph]. Furthermore, Baumgardener (1993) examined three structures of the BE ditransitive complementation: (a) Indirect object keeps prepositional object, (b) Indirect object keeps that clause object and (c) Prepositional phrase idiom.

\section{RESEARCH METHODOLOGY}

The present research uses descriptive-qualitative research approach. As per the nature of research method, the study collected samples from Pakistani Print Media English and thereby the empirical data findings were analyzed, described, compared, interpreted and explained objectively. Having considered research method in view, the present study has employed convenience sampling for data collection. According to Dörnyei (2007), this nonrandom type of sampling draws such participants who are eager to participate, available at the given time, timely reachable, and meeting to the nature of the study. Besides, this sampling type is also known as Accidental Sampling.

Pakistani Print Media English that is comprised of: PE newspapers, Dailies, Magazines and Weeklies. The research sample includes: International The News (IN), Dawn Young World (DYW), Us magazine: International The News (UIN), Business Recorder (BR), Roshni Magazine (RM) as the purpose behind the usage of abovementioned sources is to provide the most convenient, updated and efficient data to generate a thorough account of the ditransitive verb complementation. A sample of 48 statements $(n=48)$ is collected from one newspaper, six daily magazines and two weekly magazines of PE. Conversely, the study identifies only $8(n=8)$ sentences out of the 48 sentences which are distributed according to the three patterns of ditransitive complementation of $\mathrm{BE}$, three by three patterns suit to the first two patterns and last remaining suit to the third pattern. In order to make comparison, the statements are transformed into $\mathrm{BE}$ as well; besides, the data is analyzed through comparative analysis. The next section discusses data analysis and discussion.

\section{DATA ANALYSIS AND DISCUSSION}

Using comparative analysis, the study employed three patterns about the BE ditransitive complementation by Baumgardener (1993), through these patterns the identified sentences are compared in order to make clear ditransitive verb deviations between PE and BE. The patterns are: (a) Indirect object holding prepositional object, (b) Indirect object holding that clause object, and (c) Prepositional phrase idiom (ibid, 1993).

As the study retrieved $(n=8)$ statements out of $(n=48)$ statements although $(n=8)$ statements were divided into three sections as per the number of patterns ditransitive verb of BE. The first two sections carried out three statements $(n=3)$ in each and the third section comprised of two statements $(n=2)$ from the PE Print Media. Moreover, the coding used for representing Print Media sources viz. International The News (IN), Dawn Newspaper (DN), Dawn Young World (DYW), Us magazine: International The News (UIN), Business Recorder (BR), Roshni Magazine (RM). The table 1 shows below the distribution of drawn sample:

Table 1: Distribution of the drawn sample 


\begin{tabular}{|c|c|c|c|c|c|}
\hline $\begin{array}{c}\text { Total Number } \\
\text { of Drawn } \\
\begin{array}{c}\text { Samples from } \\
\text { PE Print } \\
\text { Media }\end{array}\end{array}$ & $\begin{array}{c}\text { Drawn } \\
\text { sample for } \\
\text { Pattern 1 }\end{array}$ & $\begin{array}{c}\text { Drawn } \\
\text { sample for } \\
\text { Pattern 1 }\end{array}$ & $\begin{array}{c}\text { Drawn } \\
\text { sample } \\
\text { for } \\
\text { Pattern 1 }\end{array}$ & $\begin{array}{c}\text { Total } \\
\text { number of } \\
\text { the drawn } \\
\text { sample }\end{array}$ & $\begin{array}{c}\text { Discard } \\
\text { sample }\end{array}$ \\
\hline $\mathrm{N}=48$ & $\mathrm{n}=3$ & $\mathrm{n}=3$ & $\mathrm{n}=2$ & $\mathrm{~N}=8$ & $\mathrm{n}=40$ \\
\hline
\end{tabular}

Representing pattern 1, Figure 1 shows the total number of the drawn sample from PE Print Media, number of the selected sample and discarded sample, as follows:

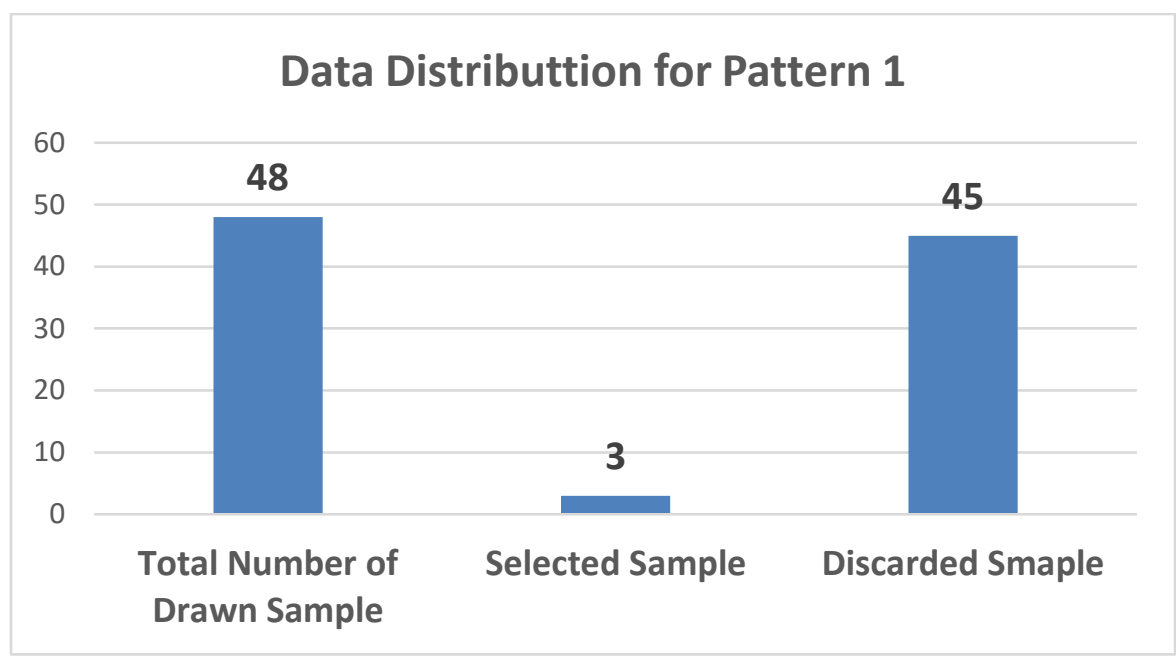

Figure 1: Data Distribution for Pattern 1

Having considered the first pattern of $B E$, the study could retrieve only $(n=3)$ statements out of $(n=48)$ statements which verified that the PE has got different syntactic representation from BE. Moreover, the drawn samples are also changed into BE ditransitive verb in order to make a reasonable comparison, as follows:

1. PE: This potentially allows incumbents to qualify both modules with A and B within a span of six months; hence, it is called a fast track system. (IN, 6 February 2015)

$\mathrm{BE}$ : This potentially allows incumbents from qualifying both modules with $\mathrm{A}$ and $\mathrm{B}$ within a span of six months; hence, it is called a fast track system.

2. PE: He became the seventh Pakistani to score a century in both innings of a Test match. (DN, 26 October, 2014)

BE: He became the seventh Pakistani for scoring a century in both innings of a Test match.

3. PE: Siraj provides five-points formula to end crisis. (IN, 15 August, 2014)

BE: Siraj provides five-points formula for ending crisis.

Above findings show that the syntactic structure of PE varies from BE in terms of ditransitive verb as PE keeps Subject + Verb + Indirect Object + Infinitive Phrase whereas BE keeps Subject + Verb + Indirect Object + Prepositional Phrase. This type of variation makes PE different from BE 
with respect to first pattern of BE which shows that the varieties of English differ from one another in terms of multiple aspects: phonologically, lexically, pragmatically, and equally syntactically. Finally, this may be deduced through above findings that English varieties vary from one another from time to time, place to place and culture to culture and whatever language variations are found in PE are also genuine and reasonable. Moreover, such variations cannot alienate PE from BE, but these variations are also confirmed by various linguists.

Conversely, in accordance with the second pattern of BE, the study finds following sentences from the selected PE Print Media in order to show syntactic variation. Moreover, identified sentences are also changed into BE so as to clarify deviations between PE and BE. Representing pattern 2, Figure 2 shows the total number of the drawn sample from PE Print Media, number of the selected sample and discarded sample, as follows:

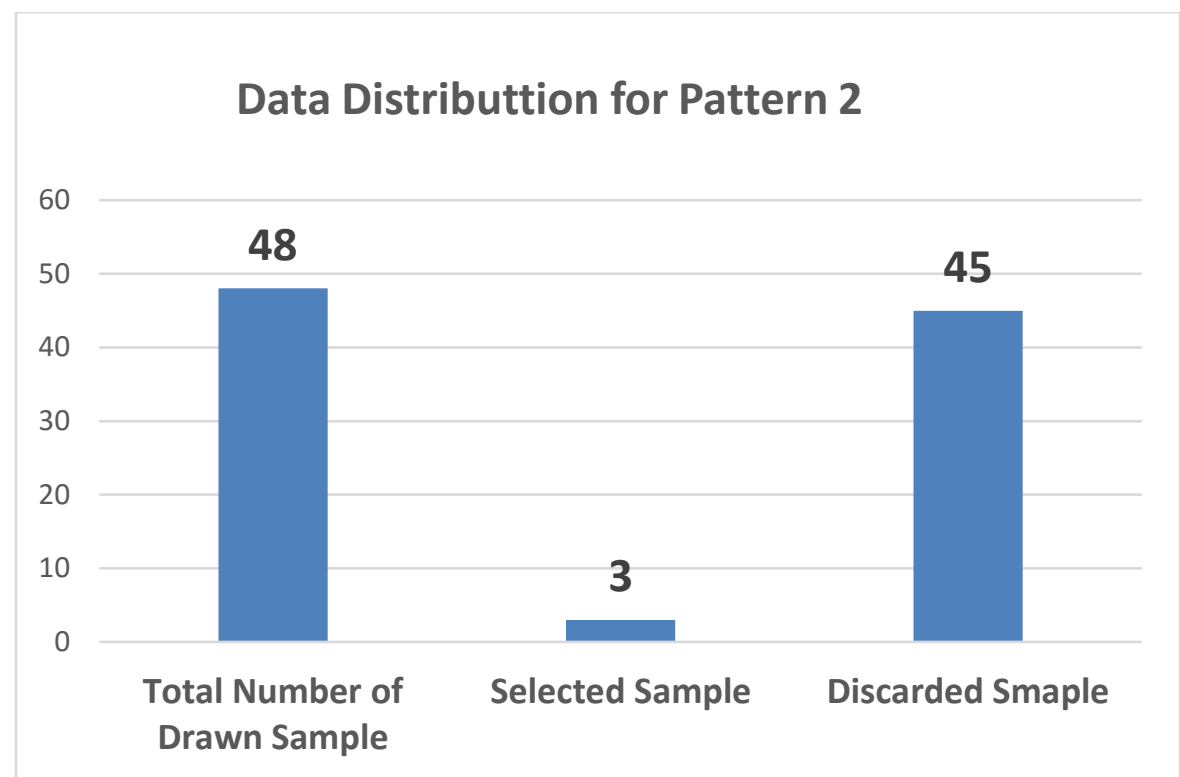

\section{Figure 2: Data Distribution for Pattern 2}

The samples for pattern 2 are given below:

1. PE: The non-profit nature ensures $(\phi)$ that the field is also considered to be among the most economical ones in the country. (UIN, 6 February, 2015)

$\mathrm{BE}$ : The non-profit nature ensures us that the field is also considered to be among the most economical ones in the country.

2. PE: He said ( $\phi)$ that these decisions would be taken in Islamabad. (IN, 15 August, 2014)

BE: He said us that these decisions would be taken in Islamabad.

3. PE: Pervaiz Khattak said $(\phi)$ that the Punjab government had made the life of citizens miserable for the last few days by blocking entire roads. (IN, 15 August, 2014)

BE: Pervaiz Khattak said us that the Punjab government had made the life of citizens miserable for the last few days by blocking entire roads.

When using ditransitive verbs, above examples show that the PE frequently omits indirect object before that clause which is represented by this symbol $(\phi)$ whereas BE always puts indirect object 
before that clause. Furthermore, this syntactic deviation between PE and BE is identified and verified through the PE Print Media as it is the most reliable and justifiable source of information collection and it also circulates news update in written form. Therefore, this study clarifies that the present world uses various varieties of English rather than one variety of English and these varieties are spoken around the world with distinctive phonological, lexical, syntactical, grammatical and discourse wise variations. Additionally, findings suggest that the PE has got different sentential structure from BE and this procedure may be defined as the linguistic growth of English.

Finally, with respect to third pattern of BE, the subsequent sentences provide a comparative account in order to make clear ditransitive verb deviation. Representing pattern 3, Figure 3 shows the total number of the drawn sample from PE Print Media, number of the selected sample and discarded sample, as follows:

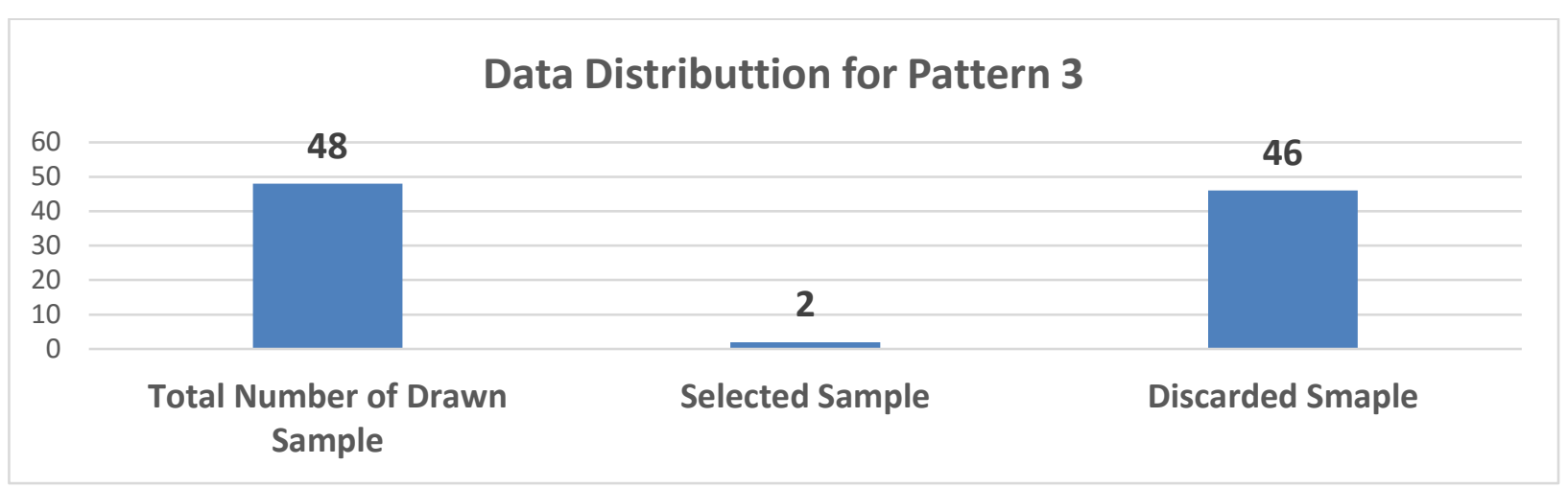

\section{Figure 3: Data Distribution for Pattern 3}

The examples for pattern 3 are given below:

1. PE: PTI continued to make deep inroads into the PPP support base. (Dawn, 15 January 2015)

BE: PTI continued no interest in making deep inroads into the PPP support base.

2. PE: Allama Dr Tahir ul Qadri wanted to bring about a revolution by wrapping up the current system and he too reminded stack to his ambition while leading his march. (IN, 15 August, 2014) BE: Allama Dr Tahir ul Qadri wanted some backup in bringing about a revolution by wrapping up the current system and he too reminded stack to his ambition while leading his march.

Above samples have showed that the PE has got different syntactic structure from BE in terms of ditransitive verbs. PE uses infinitive phrase in place of preposition and gerund idioms although this type of variation between $\mathrm{PE}$ and $\mathrm{BE}$ verifies ditransitive verb complementation. Structural representation of PE is: $\mathrm{S}+\mathrm{V}+$ to infinitive whereas $\mathrm{BE}$ has got this structure: $\mathrm{S}+\mathrm{V}+$ indirect object + prepositional idiom. 
Finally, the present study identifies these three varying patterns of PE: (a) Indirect object plus to infinitive phrase, (b) Indirect object will be omitted whereas that clause object will remain the same, and (c) to infinitive will substitute prepositional phrase idiom.

\section{Delimitations}

The present study identifies these delimitations: Firstly, the sample size is quite small which requires ten statements for each pattern and the Pakistani Print Media sources need to be increased. Secondly, there may be drawn British Print Media sources so that first-hand information may be collected. Thirdly, the study has only compared PE with BE using analytical discussion, tables and figures rather than using data analysis tools and software namely, CLAWS7 Tagger, British English 2006 (BE06), Corpus Query Processor Web (CQPweb) to validate research data. In addition, this research endeavor might be more feasible and more effective when the researcher conducts other related variations such as: dative. Nevertheless, the results of the study can be practicable for further studies between PE and BE.

\section{CONCLUSION}

Throughout the present study, findings emerged with the interpretation that PE varies from BE in terms of ditransitive complementation. This study also confirms the findings of the earlier studies (Baumgardner, 1993, Mehboob, 2003) regarding ditransitive complementation. Although, a set of three patterns of BE ditransitive verb complementation given by (ibid., 1993) used for the purpose of identifying and proving specific type of deviation between PE and BE. With this regard, the adapted patterns highly assisted in the research procedure as: first of all, PE uses infinitive phrase at the place of the direct object and that makes deviation between two considered varieties of English; at the second place, in PE indirect object is omitted and that clause remains the same between the two compared varieties of English; and at the third place, in PE sentence structure infinitive phrase is utilized instead of indirect object and prepositional idiom. In conclusion, the results have showed that both varieties of English differ at the sentential level as well as intersentential level. Moreover, this study has also opened door for the new researchers to investigate the forthcoming language change and development between aforementioned varieties of English.

\section{REFERENCES}

Ágel, V., \& Fischer, K. (2009). Dependency grammar and valency theory. In The Oxford Handbook of Linguistic Analysis.

Aziz, M, S. \& Mahmood, A. (2012). Ditransitive Verbs: A Corpus based Comparison of Pakistani and British Written English. Wulfenia Journal KLAGENFURT, AUSTRIA, 19(11).

Baumgardner, R. J. (1987). Utilizing Pakistani newspaper English to teach grammar. World Englishes, 6(3), 241-252. 
Baumgardner, R. J. (1990). The indigenization of English in Pakistan. English today, 6(1), 59-65.

Baumgardner, R. J. (1993). The English Language in Pakistan. Oxford University Press, USA.

Baumgardner, R. J., Kennedy, A. E., \& Shamim, F. (1993). The Urduization of English in Pakistan. The English language in Pakistan, 83-203.

Boyadzhieva, E. (2009). DITRANSITIVES AND THEIR ARGUMENTS IN MODERN ENGLISH. Езиков свят-Orbis Linguarum, (2), 218-227.

Carrio, P. M. (1969). Contrastive analysis of scientific-technical discourse: Common writing errors and variations in the use of English as a non-native language (Spanish text).

Carrió-Pastor, M. L. (2013). A contrastive study of the variation of sentence connectors in academic English. Journal of English for Academic Purposes, 12(3), 192-202.

Crystal, D. (1999, June). World English: past, present, future. In Proceedings of the ASKO EuropaStiftung Symposium (pp. 11-13).

Dörnyei, Z. (2007). Research methods in applied linguistics. New York: Oxford University Press.

Herbst, T., Heath, D., Roe, I. F., \& Götz, D. (2004). A valency dictionary of English. New York: Mouten de Gruyter.

Homberger, D. (2001). Grammatik für den Deutschunterricht Leipzig: Ernst Klett Schulbuchverlag.

Kachru, B. B. (1990). World Englishes and applied linguistics. World Englishes, 9(1), 3-20.

Kachru, B. B. (1997). World Englishes and English-using communities. Annual review of applied linguistics, 17, 66-87.

Kachru, B. B. (2005). Asian Englishes: beyond the canon (Vol. 1). Hong Kong University Press.

Kachru, B. B. (2006). World Englishes and Culture Wars. The handbook of world Englishes, 446470.

Kachru, B. B. (Ed.). (1992). The other tongue: English across cultures. University of Illinois Press.

Kirkpatrick, A. (2007). World Englishes paperback with audio CD: Implications for international communication and English language teaching. Cambridge University Press.

Mahboob, A. (2003). The English language in Pakistan: A brief overview of its history and linguistics. Pakistan journal of language, 4(1), 1-28.

Malchukov, A., Haspelmath, M., \& Comrie, B. (2010). Ditransitive constructions: a typological overview. Studies in ditransitive constructions: A comparative handbook, 1, 64. 
Pastor, M. L. C. (2002). The use of phrasal verbs by native and non-native writers in technical articles. In Domain-specific English: textual practices across communities and classrooms. 233-246.

Pastor, M. L. C. (2007). La variación en el uso de las expresiones de certeza en los textos científicos. Bells: Barcelona English language and literature studies, 16. 1-13.

Pastor, M. L. C. (2009). Contrasting specific English corpora: Language variation. International Journal of English Studies, 9(3), 221-234.

Qi, X. U. (2013). A corpus-based study of the alternating ditransitive verb TELL in native and Chinese learner English corpora. ICAME Journal, 37(2), 185-205.

Quirk, R. G. S, Leech, G. and Svartvik, J. (1985). A Comprehensive Grammar of the English Language. Essex: Longman Group Ltd.

Rahman, T. (1990). Pakistani English. Published by National Institute of Pakistan Studies. Islamabad.

Rahman, T. (1996). Language and Politics in Pakistan. Karachi: Oxford University Press.

Salonen, T. (2009). The Complements of the Verb hesitate from the 18th Century to the Present Day (Master's thesis). University of Tampere, Finland.

Uzair, M., Mahmood, A., \& Khan, U. (2012). Impact of Lexical Deviations in Pakistani English Newspapers on the Language of their Readers: A Gender-wise Analysis. International Journal of Business and Social Science, 3(5), 181-186.

Yule, G. (2016). The study of language. Cambridge University Press.

\begin{tabular}{|l|l|}
\hline CC) & $\begin{array}{l}\text { @ } 2017 \text { by the author. Licensee University of Chitral, Journal of Linguistics \& } \\
\text { Literature, Pakistan. This article is an open access article distributed under the } \\
\text { terms and conditions of the Creative Commons Attribution (CC BY) } \\
\text { (http://creativecommons.org/licenses/by/4.0/). }\end{array}$ \\
\hline
\end{tabular}

